\title{
Karya-Karya Seni Rupa Kontemporer Indonesia Berbasis Media Kertas: Bentuk Dan Wacana
}

\author{
Andryanto Rikrik Kusmara \\ Fakultas Seni Rupa dan Desain, Institut Teknologi Bandung \\ twinrik@gmail.com
}

\begin{abstract}
Penelitian ini menelaah karya-karya 23 seniman kontemporer Indonesia dalam memanfaatkan media kertas. Karya-karya berbasis media kertas dalam medan seni rupa Indonesia sejak era tahun 2000-an menunjukkan perkembangan yang semakin kompleks di tengah apresiasinya yang masih dipandang lebih rendah dari pada seni lukis. Permasalahan utama pada penelitian ini adalah mengkaji faktor-faktor apa saja yang menjadi indikator perkembangan seni rupa berbasis media kertas dewasa ini. Penelitian ini menggunakan pendekatan morfologi seni dengan mengurai unsur-unsur bentuk dan maknanya melalui struktur media seni. Penelitian ini merangkum diversifikasi bentuk penggunaan media kertas dalam seni rupa kontemporer Indonesia dan menunjukkan perkembangan wacana dalam seni rupa Indonesia; yang pertama adalah aspek teknologi bahan dan ketersediaan bahan kertas berkualitas, yang kedua adalah mediasi nilai-nilai media berbasis kertas, yang ketiga adalah pelestarian dan konservasi dan keempat adalah manajemen dan distribusi.
\end{abstract}

Kata Kunci : Seni rupa berbasis kertas, media seni, seni rupa kontemporer Indonesia

\section{Indonesian Contemporary Paper-Based Media Art Works: Forms And Discourse}

This study examines the works of 23 contemporary Indonesian artists in utilizing paper-based media. Paper-based works in Indonesian art world since the era of the 2000s have shown increasingly complex developments in the midst of their appreciation which are still seen as inferior to painting. The main question in this study is to examine what factors are indicators of the development of paper-based media art today. This study uses a morphological approach to art by parsing the elements of form and meaning through the structure of art media. This research summarizes the diversification of the use of paper media in Indonesian contemporary art and shows the development of discourse in Indonesian art; the first is the material technology aspect and the availability of quality paper material, the second is the mediation of paper-based media values, the third is conservation and conservation and fourth is management and distribution.

Keywords : paper based art, art media, Indonesian contemporary art

Proses Review : 1 - 18 April 2019, Dinyatakan Lolos: 22 April 2019 


\section{PENDAHULUAN}

Kertas merupakan material konvensional seni rupa yang memiliki posisi yang khas dalam perkembangan sejarah seni rupa. Secara umum di Indonesia pemanfaatannya dalam konteks seni rupa digunakan dalam pendekatan konvensional sebagai bahan lembaran seperti untuk menggambar (drawing), lukisan cat air atau media seni grafis untuk menempatkan representasi gambar. Kemudian secara hirarki apresiasi media seni di Indonesia karya berbasis material kertas secara umum masih diposisikan lebih rendah daripada karya karya seni lukis. Hal ini disebabkan stereotype cara pandang masyarakat yang melihat bahan kertas sebagai material yang kurang tahan terhadap iklim yang lembab, ringkih dan lebih sulit dalam hal perawatan (konservasi) dibandingkan dengan media tradisional lain seperti misalnya seni lukis pada kanvas. Dan oleh sebab itu juga karya-karya kertas umumnya memiliki nilai ekonomis lebih rendah.

Penelitian ini diharapkan dapat menemukan perkembangan baru dalam karya-karya berbasis kertas di Indonesia, wacana yang berkembang dalam kurun waktu dua dekade terakhir dan bagaimana posisi karya-karya berbasis material kertas dalam medan seni rupa Indonesia, sehingga penelitian ini dapat melengkapi informasi terkait kondisi ekosistem seni rupa Indonesia serta meningkatkan apresiasi perkembangan seni rupa kontemporer khususnya bagi karya-karya berbasis media kertas.

\section{METODE PENELITIAN}

Penelitian ini secara mendasar akan mengkaji medium seni berbasis kertas dalam praktek seni rupa kontemporer Indonesia. Perspektif penelitian yang dikembangkan adalah mengkaji struktur bentuk medium seni melalui kecenderungan paradigmatis penghadiran media seni yang terjadi dalam praktek seni rupa kontemporer Indonesia.

Penelitian akan menguraikan struktur media seni berbasis kertas dalam praktek seni rupa kontemporer Indonesia, dengan mengurasi hal hal yang bersifat estetik kualitatif. Untuk itu penelitian ini akan menggunakan metode kualitatif, yang secara prinsip digunakan berdasarkan masalah yang akan dikaji.

Prosedur yang digunakan adalah cara kerja induktif atau penetapan kebenaran suatu hal atau perumusan umum mengenai suatu gejala dengan cara mempelajari kasus atas kejadian khusus yang berhubungan dengan hal tersebut. Cara kerja ini untuk menarik kesimpulan dari hal-hal yang khusus untuk menuju yang umum. Menghasilkan kerangka pemahaman umum tentang karya-karya berbasis media kertas dengan membuka ruang kemungkinan simpulan dari kekuatan deskripsi dan melihat gejala-gejala paradigmatisnya.
Penelitian ini bertujuan menelaah karya-karya seni rupa kontemporer Indonesia berbasis material kertas yang berkembang dalam dua dekade terakhir. Pengkajian ini dilakukan untuk melihat varian bentuk-bentuk ekspresi dan wacana mutakhir yang berkembang pada karya-karya bebasis kertas. Penelitian ini juga mengumpulkan berbagai karya-karya seniman kontemporer Indonesia dalam kurun waktu dua dekade yang memanfaatkan media kertas dalam karya-karyanya, dengan menggunakan metode penelitian pendekatan teoritik struktur media seni Davies, D. ( 2003): Medium in Art, dalam Levinson, J (ed), untuk mengurai dan mengkaji kecenderungan karya-karya yang dibuat seniman dan menganalisis wacana mengenai media kertas baik yang dibuat oleh seniman maupun dari sumber-sumber pustaka lainnya terkait karya, seniman dan pameran yang memanfaatkan media berbasis kertas.

\section{Kajian Perkembangan Karya-Karya Berbasis Kertas di Indonesia}

Sejak Gerakan Seni Rupa Baru (GSRB) di Indonesia muncul dalam pameran di tahun 1975 di Taman Ismail Marzuki Jakarta sebagai gerakan ekspresi pemberontakan seni rupa yang menolak dominasi seni lukis sebagai karya seni yang dianggap baik pada masa tersebut, kemudian melahirkan praktek-praktek seni rupa dan pemikiran yang membuka kesadaran baru bagaimana bentuk-bentuk seni rupa modern Indonesia dibaca dan dimaknai. GSRB menjadi salah satu tonggak penting dalam sejarah perkembangan praktek dan wacana estetik seni rupa Indonesia dalam perkembangan praktek seni rupa dan wacana media seni rupa.

GSRB sebagai gerakan terobosan estetik kemudian memberikan pengaruh yang sangat besar dalam perkembangan seni rupa Indonesia pada tahun tahun berikutnya, khususnya dalam pendekatan seniman melakukan eksplorasi dan redefinisi media seni rupa. Seperti pada kegiatan pameran Pasar Raya Dunia Fantasi tahun di Taman Ismail Marzuki 1987 yang juga menolak definisi seni yang terpusat pada seni lukis, seni patung dan seni grafis, serta Pameran Biennale IX Jakarta di Taman Ismail Marzuki 1993 yang juga menampilkan kecendederungan untuk menolak bentuk bentuk media konvensional seperti lukis, patung dan seni grafis dan menampilkan karya-karya yang memiliki kencerungan intermedia dan instalasi. (Kusmara, AR, 1999)

Perkembangan praktek dan wacana seni rupa sejak GSRB hingga Biennale IX Jakarta telah memantapkan sebuah kecenderungan konsepsi prinsip-prinsip estetik yang baru dengan semakin kuatnya pendekatan intermedia dan instalasi dalam eskpresi karya-karya seniman pada masa tersebut. Eksplorasi media pada era seni rupa Indonesia 90-an tersebut telah melahirkan konsep seni rupa kontemporer Indonesia yang mendorong praktek seni rupa menjadi lebih beragam yang dikembangkan sjak seni rupa 80'an yang banyak menunjukkan gejala pemberontakan. (Supangkat, 1993) 
Kecenderungan beragam pendekatan media seni rupa di era 90-an juga telah menjadi titik berangkat sejarah seni rupa Indonesia dengan dengan semakin mapannya perpektif baru pendekatan estetik yang meleburkan batas-batas konvensi menjadi media seni menjadi eksplorasi karyakarya dengan berbagai pendekatan media termasuk karyakarya baik yang secara langsung maupun tidak langsung melibatkan bahan kertas maupun mixmedia pada kertas.

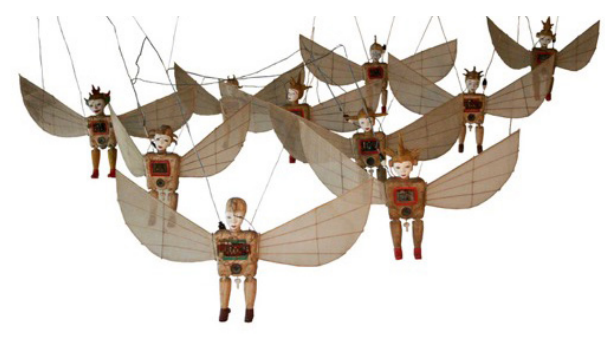

Gambar 1. Heri Dono 1991 Papermache Mixmedia.jpg. (Sumber : https://indoartnow.com/artists/heri-dono)

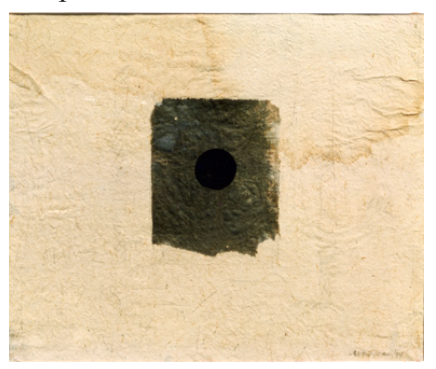

Gambar 2. Setiawan Sabana, Untitled, Mixmedia kertas, 1994. (Sumber : Setiawan Sabana)

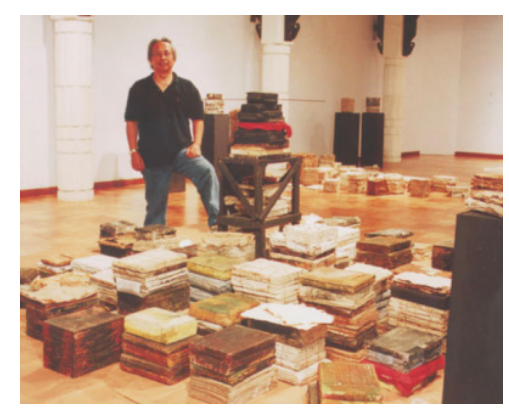

Gambar 3. Setiawan Sabana . "Monumen Kertas", Installation 2005, (Sumber : Setiawan Sabana)

Pemahaman kontemporer sejak era 90-an dalam pemanfaatan material kertas menunjukkan pendekatan baru, kertas tidak lagi dipandang hanya dalam konteks material dan media tradisionil untuk menggambar atau melukis, namun juga mulai meluas pada pemahaman kertas dalam konteks budaya, lingkungan dan peluangnya sebagai bentuk tiga dimensi, seperti pada contoh karya Heri Dono dan Setiawan Sabana.

Perkembangan pemanfaatan material kertas dalam perkembangan seni rupa kontemporer Indonesia dalam dua dekade terakhir menunjukkan perkembangan yang semakin beragam, dalam kajian yang dilakukan pada seniman-seniman yang memanfaatkan material kertas yaitu
Srihadi Soedarsono, Heri Dono, Entang Wiharso, Setiawan Sabana, Eko Nugroho, Nandang Gawe, Intan Subagyo, Agus Suwage, Handiwirman, Irfan Hendrian, Mujahidin Nurrahman, Rudi Atjeh, Tisna Sanjaya, Tita Ruby, Yudi Sulityo, Valasara, Patriot Mukmin, Debora Patricia, Guntur Timur, Zusfa Roihan, Wayan Upadana, Wayan Sujana 'Suklu', Ardiyanto. Menunjukkan perkembangan kertas sebagai material seni semata kemudian bergeser menjadi kertas sebagai media seni.

Penelitian ini menggunakan kajian dan analisis struktur media seni yang merupakan satu bidang dalam seni yang mengkaji pendekatan seniman dalam mengkonstruksi pesan dan kode-kode estetik pada material dan teknik seni. Media seni adalah konvensi teknik dan material seni sebagai wahana bagi seniman menempatkan representasi ekspresi dan konsep-konsep seni nya.

Perkembangan media seni ini menempatkan struktur konvensi teknik dan material menjadi salah satu pembahasan estetika sebagai 'medium seni' atau wahana perantara seniman mengkomunikasikan konsep dan ekpresi seni dalam bentuk pesan pesan seni. Struktur media seni rupa tersebut dapat digambarkan sepertti pada bagan di bawah ini.

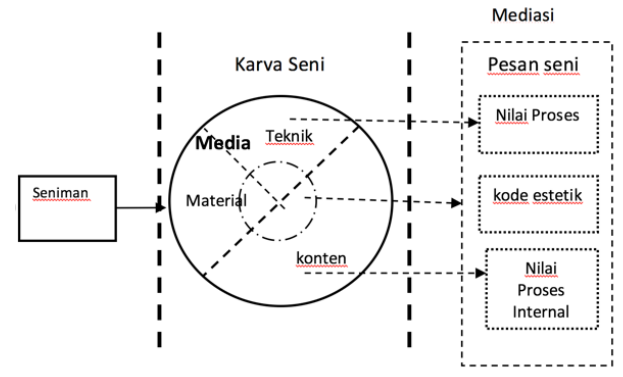

Bagan 1. Bagan Media dan Komunikasi Seni. (Sumber : Kusmara, AR.2011)

\section{Bentuk-Bentuk Karya Seni Rupa Kontemporer Berba- sis Media Kertas}

Dari penelitian terhadap bentuk karya-karya yang dibuat seniman yang memanfaatkan media kertas di atas terbagi ke dalam :

a. kertas sebagai media konvensional seperti lukis atau cetak grafis namun dibuat dengan pendekatan baru.

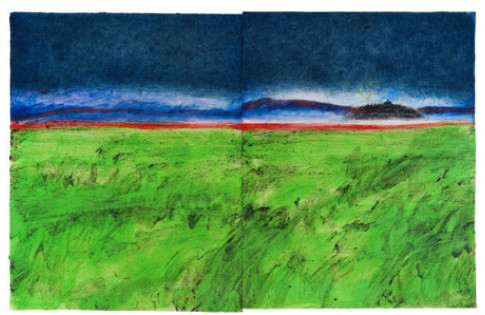

Gambar 4. Srihadi Soedarsono, Borobudur, Singapore Tyler Prints Institute. (STPI). Custom made paper, 2005.

(Sumber : Peneliti) 


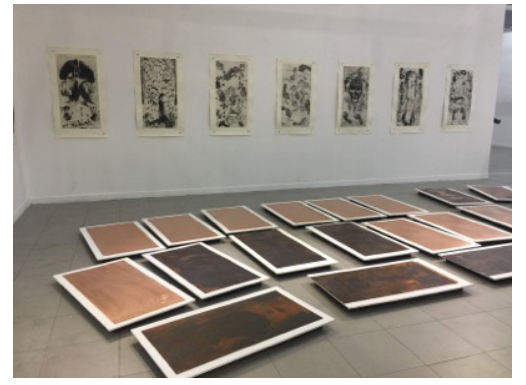

Gambar 5. Tisna Sanjaya, Sujud dari 99 nama yang Indah, Etsa pada Kertas dan Instalasi. 2018. (Sumber : Peneliti)

b. Pendekatan ekplorasi bentuk dari bahan bubur kertas.

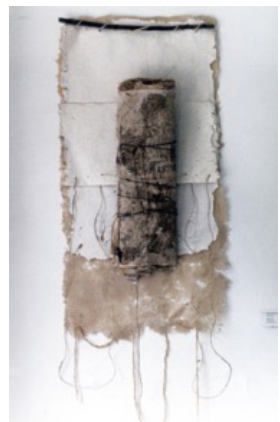

Gambar 6. Setiawan Sabana, Seri Monumen Kertas, Mixmedia Bubur Kertas. 2005. (Sumber : Peneliti)

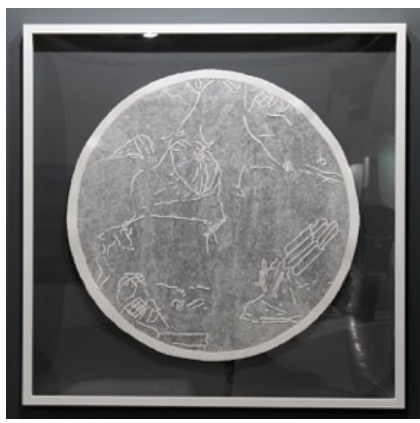

Gambar 7. Handiwirmasn Saputra, Ujung Sangkut Sisi Sentuh I \#04/Suspended Form Project STPI.Paper pulp drawing with translucent abaca paper. 2012. (Sumber : Peneliti)

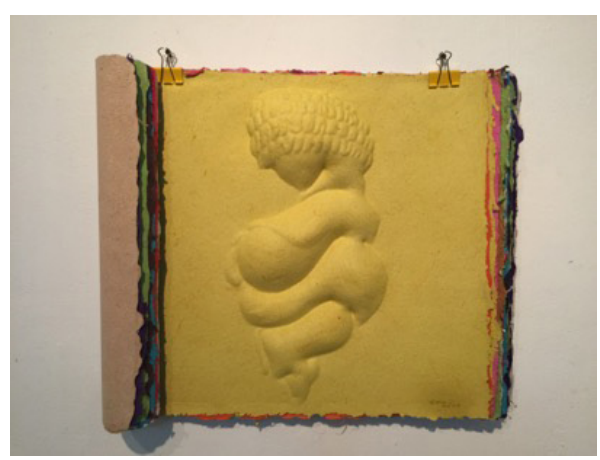

Gambar 8. Valasara, Venus, Recycle dan Cetak Kertas (paper casting). 2018

\section{c. Pendekatan ekplorasi bentuk dari bahan dasar lem- baran kertas industri.}

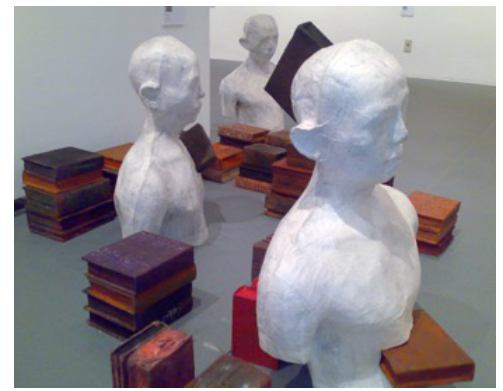

Gambar 9.Setiawan Sabana, Jagat Kertas, Paper Casting (cetak kertas). 2011. (Sumber : Peneliti)

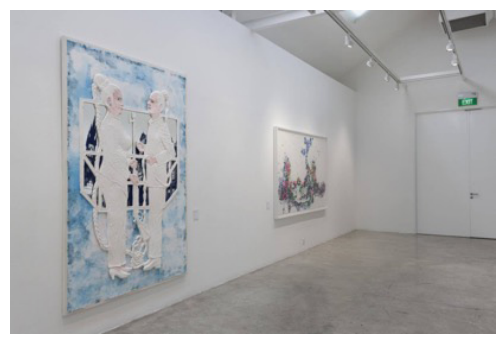

Gambar 10. Etang Wiharso, Never Say No, Project STPI, paper-casting technique, 2015. (Sumber : Peneliti)

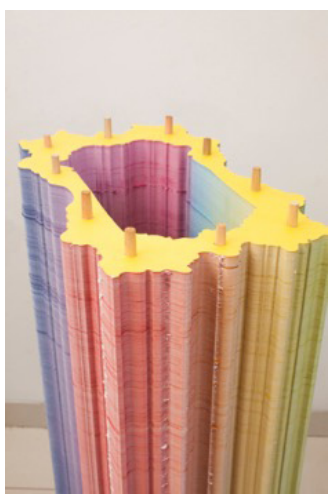

Gambar 11. Irfan-Hendrian, Piles of Inks on Paper offset lithography on stacks of paper and wood 3 retouched. 2018 (Sumber : Peneliti)

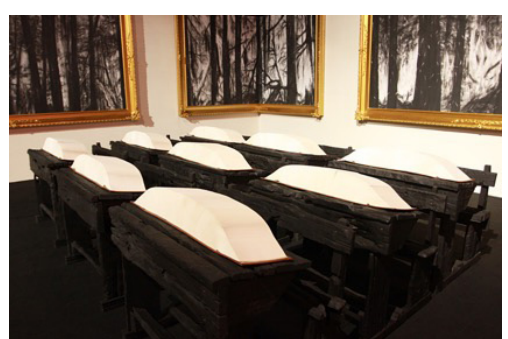

Gambar 12. Tita Ruby, Bacalah, Instalasi kayu kertas, lukisan. 2012 (Sumber : Peneliti) 


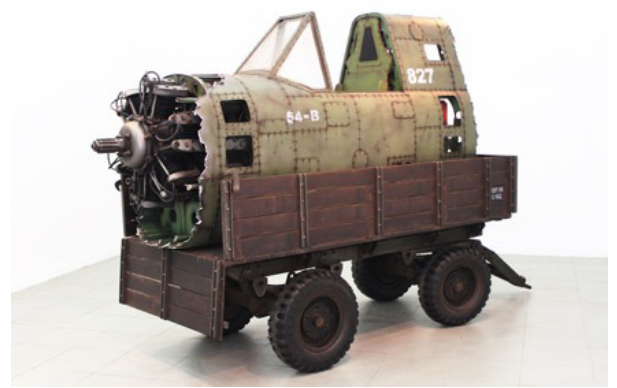

Gambar 13. Yudi Sulistyo, Yang Terlupa, Kertas, pipa PVC, kayu, kabel, cat, barang bekas 2013. (Sumber : Peneliti)

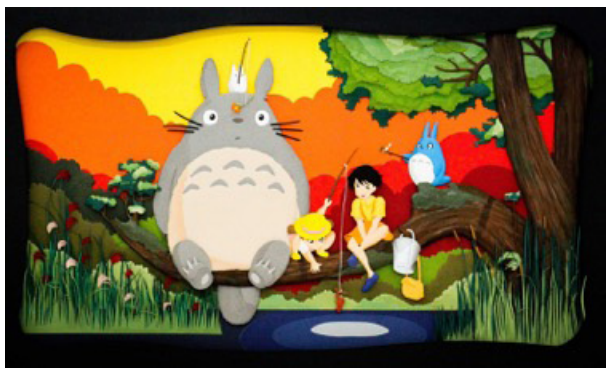

Gambar 14. Intan Subagio, My Neighbor Totoro, Papercutting, 2015. (Sumber : Peneliti)

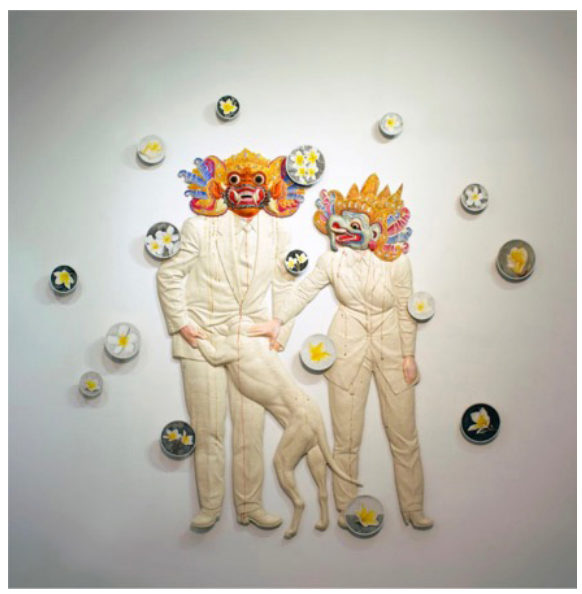

Gambar 15. Agus Suwage, Kama Sutra II, papier-mâché, gouache, watercolor, tobacco juice. 2016

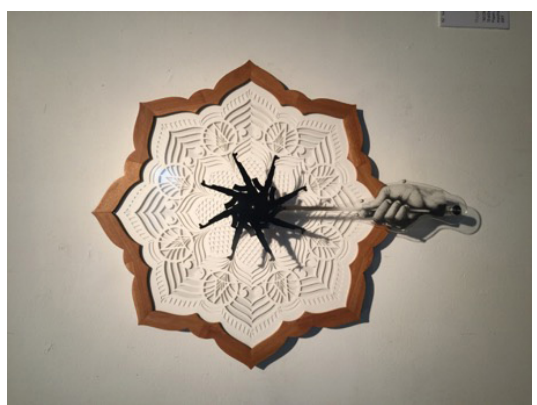

Gambar 16. Mujahiddin Nurrahman, all Children Go to Heaven, mixmedia Manual Papercutting. 2017 d. Pendekatan Pengolahan bentuk dari benda benda temuan (ready-mades dan found object) berbahan Kertas

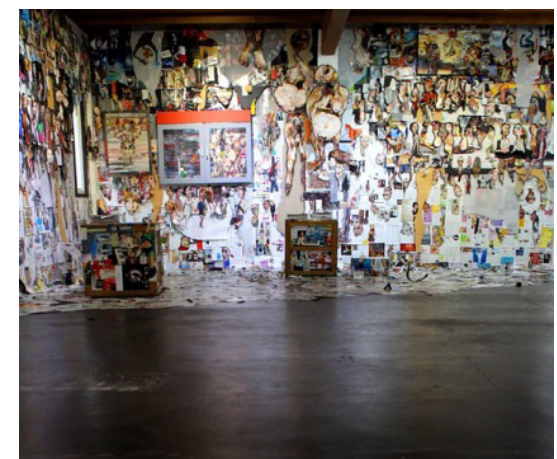

Gambar 17. Nandang Gawe, Instalasi, Guntingan kertas majalah. 2018. (Sumber : Peneliti)

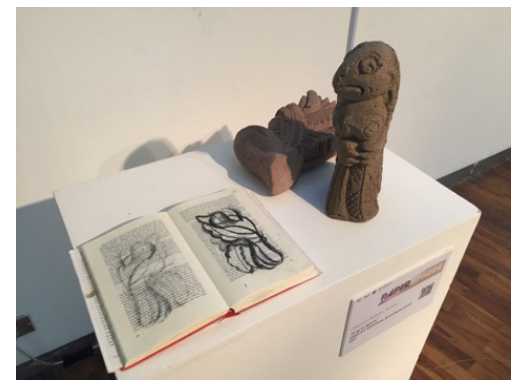

Gambar 18. Suklu, Project Drawing Novel. 2017.

(Sumber : Peneliti)

\section{Wacana karya kontemporer berbasis kertas}

Perkembangan wacana media kertas telah mengalami perubahan dalam dua dekade terakhir ini, wacana kertas telah bergeser menjadi pendekatan media atau sebagai konvensi teknik pada material, menghasilkan karya kontemporer berupa pertama, media konvensional yang dihadirkan dengan pendekatan baru, kedua ekplorasi teknik dan bentuk karya dari bahan dasar bubur kertas (pulp), ketiga ekplorasi media dari bahan kertas industri dan ke empat pendekatan readymades dan found object. Kertas telah menjadi media seni rupa

Pemahaman kertas selain sebagai media konvensional ( sebagai bahan drawing, lukisan cat air) serta cetak grafis juga bagi perupa kontemporer Indonesia telah berkembang menjadi spektrum luas kemungkinan kreatif, dengan banyak pemanfaatan secara ekploratif dan eksperimentatif bahan bubur kertas, menjadi objek tiga dimensi, pemanfaatan bahan daur ulang (recycle), sebagai benda temuan (found object) dan olahan benda jadi (readymades) yang kemudian menjadi karya-karya seni rupa kontemporer Indonesia.

Salah satu fenomena faktor penyebab keragaman media kertas dalam seni rupa kontemporer Indonesia juga adalah seniman-seniman yang diundang dalam program residensi di Singapore Tyler Prints Institute (STPI) dian- 
taranya, Srihadi Soedarsono, Heri Dono, Entang Wiharso, Eko Nugroho, Agus Suwage, Handiwirman. Pada karyakarya yang dibuat kurun waktu 2000-2017 di STPI ini menunjukkan kecenderungan ekplorasi media kertas yang memiliki kualitas teknik yang cukup tinggi, disebabkan lembaga STPI tersebut sebagai bengkel kerja yang memiliki fasilitas lengkap baik, teknologi dan sumber daya manusia (teknisi) yang professional dalam mendukung ideide kekaryaan seniman. Oleh sebab itu karya-karya yang dibuat oleh seniman Indonesia di STPI menunjukkan sisi teknik yang kuat yang cukup sulit dilakukan tanpa fasilitas lengkap bengkel kerja dan menjadi benchmark bagaimana perlakuan kelembagaan seni dalam media kertas.

Perubahan lain dari perkembangan karya-karya bebasis kertas adalah munculnya seniman-seniman kontemporer Indonesia yang memiliki spesialisasi media kertas, seperti Irfan Hendrian, Mujahiddin Nurrahman, Rudi Atjeh, Intan Subagio dan Yudi Sulistyo. Seniman-seniman ini juga telah memiliki reputasi nasional dan internasional dalam forum pameran yang diikutinya, hal ini menunjukkan seniman dan karya media kertas yang telah memiliki apresiasi yang tinggi secara khusus seniman-senian seperti Irfan Hendrian, Yudi Sulistyo dan Mujahiddin Nurrahman memiliki manajer yang khusus mengelola kegiatan artistik mereka.

\section{SIMPULAN}

Sejak material kertas ditemukan dan kemudian menjadi media untuk penulisan text juga media representasi gagasan gagasan melalui gambar, bersama itu tumbuh juga berbagai inovasi teknologi material kertas dan gagasan-gagasan kreatif dalam merespons spektrum potensi kertas baik sebagai material maupun media representasi seni. Kertas yang pada awalnya dipandang sebagai bahan lembaran kosong untuk menggambarkan dan menyimpan world view seniman melalui pendekatan menggambar (Dexter, 2015), dalam perluasan dan perkembangan wacana seni serta dalam konteks industri dan budaya visual (visual culture) dewasa ini menunjukkan gejala diversivikasi kreatifitas pemanfaatan media kertas yang luar biasa di medan seni Indonesia.

Bahan kertas juga sebagai media yang kini banyak di eksplorasi para seniman memiliki karekter yang spesifik atau medium specificity, dimana material dan teknis tertentu secara artistik memiliki kualitas dan efek spesifik (Bernstein, 2004), seperti misalnya pendekatan bahan bubur kertas, papermache atau papercut. Hal menunjukkan baik secara bentuk maupun wacana media berbasis kertas memiliki potensi artistik (artistik media) yang luas.

Dalam kondisi medan seni rupa dimana karya-karya media kertas telah berkembang dan menjadi konvensi media yang telah mulai diterima masyarakat, dalam konteks eko- sistem seni rupa kemudian muncul tiga aspek penting yang menjadi wacana baru bagi para pelaku ekossitem seni rupa terkait media berbasis kertas, yaitu pertama ketersediaan material yang berkualitas dengan harga terjangkau, kedua adalah mediasi nilai-nilai karya berbasis kertas, ketiga pengetahuan preservasi dan konservasi dan ke empat adalah manajemen dan distribusi.

\section{DAFTAR RUJUKAN}

Davies, D. ( 2003): Medium in Art, dalam Levinson, J (ed.), The Oxford Handbook of Aesthetics, Oxford University Press, New York, $181-191$.

Dexter, Emma, (2015). Vitamin D : New Perspective in Drawing, Phaidon Press, 008-009.

Kusmara, A. R. (1999): Seni Instalasi dalam Seni Rupa Kontemporer Indonesia, Tesis Program Magister Seni Rupa, Institut Teknologi Bandung, 27-38.

Kusmara, A.R. (2011) Media Seni dalam Seni Rupa Kontemporer Indonesia, hal.36.

Supangkat, J. (1993): Seni Rupa Era 80. Katalog Biennale Seni Rupa Jakarta IX, hal 13.

Bernstein, Emma Bee, Medium Specificity, Theories of Media, The University Of Chicago. http://chicagoschoolmediatheory.net/glossary2004/specificity.htm 